
\title{
THE PROTOTYPIC NUTRITIONAL ASSESSMENT
G) AND THE PARSING OF THE NUTRITIONAL CRITICAL GALEAZZI CONTROL POINTS (NCCP) IN ORTHOPEDICS.
}

\author{
Briguglio $\mathrm{M}^{1}$, Banfi $\mathrm{G}^{1,2}$, Vitale $\mathrm{JA}^{3}$, Sirtori $\mathrm{P}^{4}$, Perazzo $\mathrm{P}^{5}$. \\ ${ }^{1}$ IRCCS Orthopedic Institute Galeazzi, Scientific Direction, 20161 Milan, Italy. \\ 2 Vita-Salute San Raffaele University, Faculty of Medicine and Surgery, 20132 Milan, Italy. \\ 3 IRCCS Orthopedic Institute Galeazzi, LaMSS-Laboratory of Movement and Sport Science, 20161 Milan, Italy. \\ 4 IRCCS Orthopedic Institute Galeazzi, Regenerative and Reconstructive Unit, 20161, Milan, Italy. \\ 5 IRCCS Orthopedic Institute Galeazzi, Post-operative Intensive Care Unit \& Anesthesia, 20161 Milan, Italy.
}

\section{Objective}

Data literature lacks of evidence concerning the variation of the nutritional status in patients undergoing orthopedic surgery, thus preventing an effective application of a nutritional support program. It is therefore necessary to start identifying the clinical steps (pre-operative and post-operative) that may define the Nutritional Critical Control Points (NCCP) for malnutrition in Orthopedics [1,2,3].

\section{Research Methods \& Procedures}

The first patients of the ongoing trial NCT03981354 are being assessed for anthropometry, biochemical markers, functional status, and dietary habits. Assessments are being applied before surgery at -1 day and after surgery at +3 and +14 days, named G3 and G14.

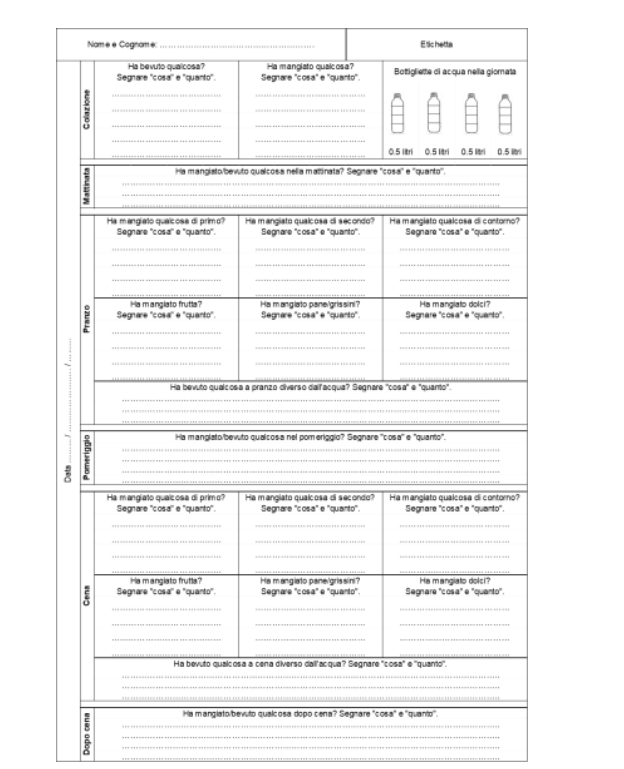

Food diary

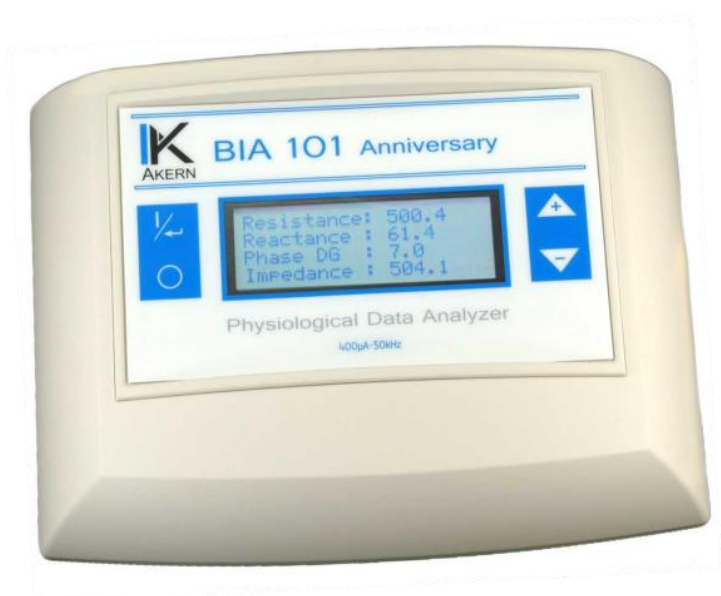

Bioelectrical impedance analysis

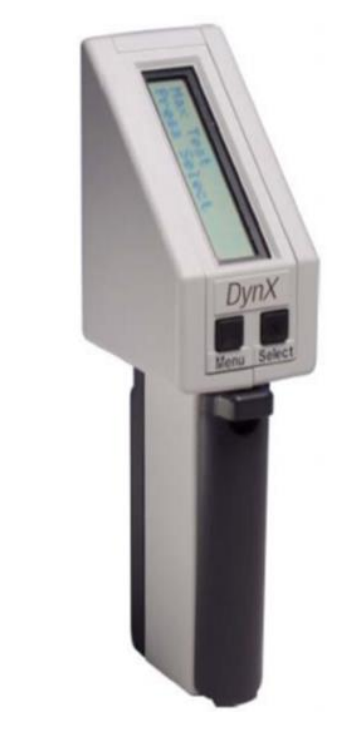

Handgrip strength

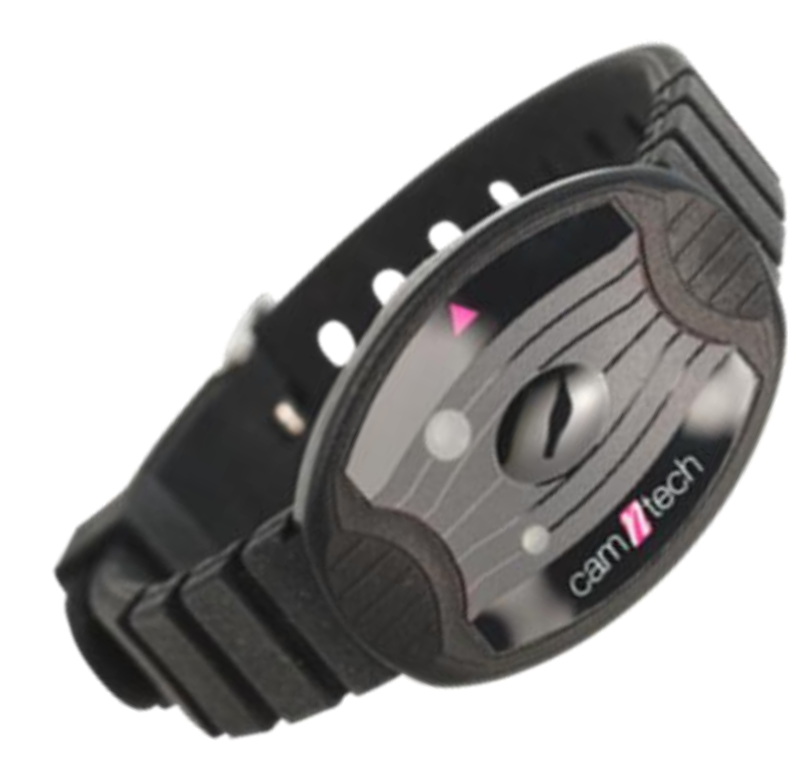

Wrist accelerometer

Table 1. The prototypic nutritional assessment of the studied patient.

\begin{tabular}{cccc} 
& G-1 & G3 & G14 \\
Body weight $(\mathrm{kg})$ & 78.1 & 80.2 & 77.2 \\
Calf $(\mathrm{cm})$ & $\mathrm{dx}: 33.2 \mathrm{sx}: 34.7$ & $/$ & $/$ \\
Phase angle & 5.9 & 5.8 & 6.2 \\
Hemoglobin $(\mathrm{g} / \mathrm{dL})$ & 14 & 10.8 & 12.5 \\
Pre-albumin $(\mathrm{g} / \mathrm{L})$ & 0.21 & 0.09 & 0.26 \\
Albumin $(\mathrm{g} / \mathrm{dL})$ & 4.4 & 3.3 & 4.4 \\
Lymphocytes $\left(10^{3} / \mu \mathrm{L}\right)$ & 1.28 & 1.18 & 1.79 \\
Iron $(\mu \mathrm{g} / \mathrm{dL})$ & 45 & 16 & 33 \\
Transferrin $(\mathrm{mg} / \mathrm{dL})$ & 296 & 187 & 291 \\
Ferritin $(\mathrm{ng} / \mathrm{mL})$ & 13 & 84 & 67 \\
25[OH]D $(\mathrm{ng} / \mathrm{mL})$ & 10.6 & ongoing & ongoing \\
\hline Handgrip strength $(\mathrm{kg})$ & $37.04 \pm 2.1$ & $34.7 \pm 3.2$ & $35.3 \pm 1.5$ \\
10-ms walking test $(\mathrm{m} / \mathrm{s})$ & 1.41 & 1.10 & 1.24 \\
MNA-Short Form & 13 & $/$ & $/$
\end{tabular}

\section{Results}

The case subject is a male of 74 y.o. $(B M I=30.13)$ suffering from gastritis, HBP, glucose intolerance, and hip osteoarthritis undergoing prosthetic implant. No complications after surgery occurred, and discharge was at G3 with home rehabilitation. In Table 1, low phase angle, lymphocyte count, ferritin, and vitamin $\mathrm{D}$ may be associated to a subclinical malnutritional status, which is not affecting the functional status yet. Analysis at G3 of daily food intake (1333 kcal $+65 \mathrm{~g}$ of proteins) and activity level $(6 h \times 1.1+12.34 h \times 1.2+5.19 h \times 1.3+0.07 h \times$ 1.4 ) is showed. Mean activity factor: 1.17 . Oral intake provides insufficient amounts of food (17 kcal $/ \mathrm{kg}$ and $0.83 \mathrm{~g} / \mathrm{kg}$ ).

Figure 1. The prototypic eating and movement assessments of the studied patient (G3).
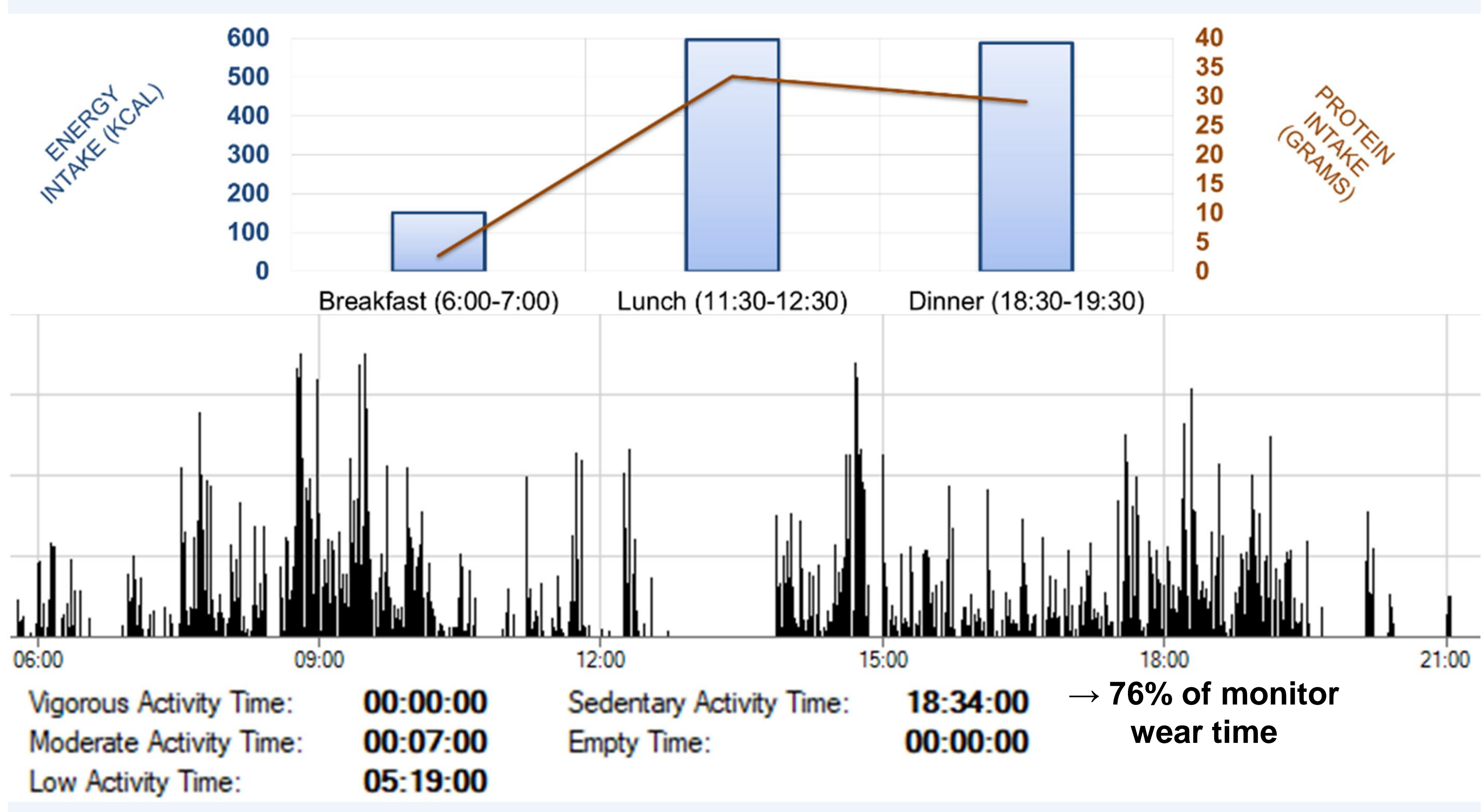

\section{Conclusions}

Giving the estimation of $1445 \mathrm{kcal} / \mathrm{die}(\mathrm{HB})$ [4] +1.2 for minor stress +1.17 activity factors, a total of $2023 \mathrm{kcal} / \mathrm{die}$ is obtained. Data shows biochemical markers that may be targeted for nutritional support, as well as quantitative and timely disproportions of food intake and motion, with highest levels of sedentary activity. Given the increasing number of orthopedic interventions each year in Italy (43705 prosthetic surgeries in 2017) [1], this preliminary assessment parsed the NCCP to be considered in Orthopedics, thus laying the groundwork for future nutrition support programs.

Figure 2. The Nutritional Critical Control Points (NCCP) in Orthopedics.

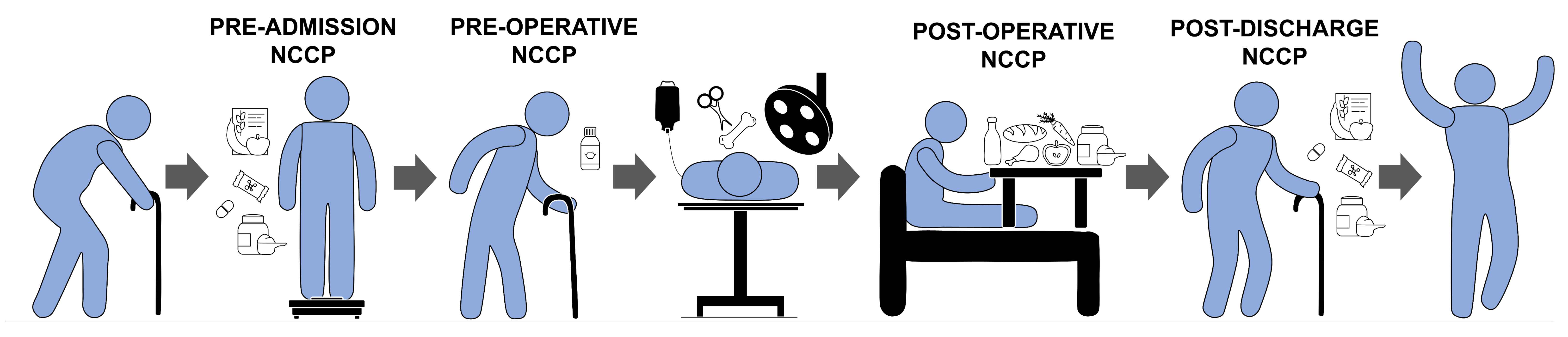

WHO SHOULD BE PART The NCCP team should include Dietitian Nutritionists, Anesthesiologists, Orthopedic Surgeons, OF THE NCCP TEAM? Pharmacists, Nurses, Physical Therapists, Psychologists, Administrative Assistants.

[1]. Briguglio M, Gianola S, Ismael Aguirre MF, et al. Nutrition Clinique et Métabolisme 2019, Sept; 33(3): 190-198.

[2]. Briguglio M, Gianturco L, Stella D, et al. J Geriatr Cardiol, 2018 Aug; 15(8): 519-522.

[3]. Briguglio M, Hrelia S, Malaguti M, et al. Pharmaceutics, 2018 Dec; 10(4): 277.

[4]. Roza AM and Shizgal HM. Am J Clin Nutr, 1984. Muller B et al. Praxis (Bern 1994). 2001 Nov 8;90(45):1955-63. 